\title{
Diagnosis of congenital esophageal stenosis in adults and treatment with peroral endoscopic myotomy
}

\author{
Haruo Ikedaa, Haruhiro Inouea, Mary Raina Angeli Abada, Yusuke Fujiyoshia, Yohei Nishikawaa, \\ Akiko Toshimoria, Mayo Tanabe a, Yuto Shimamura ${ }^{a}$, Kazuya Sumi ${ }^{a}$, Yugo Iwaya ${ }^{a}$, \\ Anastassios Manolakis ${ }^{b}$, Manabu Onimarua
}

Showa University Koto Toyosu Hospital, Tokyo, Japan; General Hospital of Athens Evangelismos, Athens, Greece

\section{Abstract}

Background Congenital esophageal stenosis (CES) in adults is a rare disorder that can present as achalasia, particularly in the distal esophagus. We describe the salient features of CES in adults and identify the feasibility and short-term outcomes of peroral endoscopic myotomy (POEM) for CES.

Methods In this retrospective, single-center case series, we included 6 patients with a "misdiagnosis" of achalasia established elsewhere, ultimately diagnosed with CES and referred to our institution for POEM. Symptom improvement (clinical success rate), defined as an Eckardt Symptom Score (ESS) of $<3$ at 2 -month follow up was assessed.

Results Six patients (median age: 40 [range: 18-58] years; 4 males) were included. A longstanding history of dysphagia, ring-shaped stenosis on endoscopic examination, "lopsided hourglass" sign on barium esophagogram, and high-resolution manometry findings indicated by a compartmentalized intrabolus pressure pattern with distinction between the stenotic area and the lower esophageal sphincter were the salient features identified. POEM could not be completed in the first 2 cases due to technical challenges. All subsequent 4 patients who underwent successful POEM, exhibited improved ESS of $\leq 3$ (clinical success rate 100\%) at 2 months post-POEM.

Conclusions Along with identification of salient features on several diagnostic modalities, a differential diagnosis of CES in adults must be considered in patients presenting with longstanding history of dysphagia arising from childhood and persisting into adulthood. Although favorable short-term outcomes of POEM were achieved, further evaluation is still warranted, and an inexperienced operator should not attempt POEM on CES patients due to its technical difficulties.

Keywords Congenital esophageal stenosis, diagnosis, peroral endoscopic myotomy

Ann Gastroenterol 2021; 34 (1): 1-8
${ }^{a}$ Digestive Diseases Center, Showa University Koto Toyosu Hospital, Tokyo, Japan (Haruo Ikeda, Haruhiro Inoue, Mary Raina Angeli Abad, Yusuke Fujiyoshi, Yohei Nishikawa, Akiko Toshimori, Mayo Tanabe, Yuto Shimamura, Kazuya Sumi, Yugo Iwaya, Manabu Onimaru); ${ }^{b}$ Department of Gastroenterology, General Hospital of Athens Evangelismos, Athens, Greece (Anastassios Manolakis)

Conflict of Interest: Haruhiro Inoue is an advisor of Olympus Corporation and Top Corporation. He has also received educational grants from Olympus Corp., and Takeda Pharmaceutical Co. Anastasios Manolakis has received grant from the Hellenic Society of Gastroenterology and research fund from Janssen Pharma

Correspondence to: Mary Raina Angeli Abad, MD, Digestive Diseases Center, Showa University Koto Toyosu Hospital, 5-1-38 Toyosu, Koto-ku, Tokyo 1358577 Japan, e-mail: raina.abadmd@gmail.com

Received 19 August 2020; accepted 28 December 2020; published online 23 March 2021

DOI: https://doi.org/10.20524/aog.2021.0618

\section{Introduction}

Congenital esophageal stenosis (CES) is a rare disorder resulting from an embryologic defect in esophageal canalization [1], occurring in 1/25,000-50,000 live births [1,2]. It is more commonly reported in the pediatric population; hence, inclusion of CES in the differential diagnosis of dysphagia in the adult population is rather infrequent. CES in adults usually presents with a long-standing history of dysphagia and malnutrition [3].

Distinguishing CES from achalasia, a motility disorder characterized by increased lower esophageal sphincter (LES) pressure and defective relaxation as well as a compromised contractile function peristalsis of the esophageal body $[4,5]$, poses a challenge particularly when CES is located in the distal esophagus. Although histologic evaluation is used to establish 
the diagnosis of CES [6], the medical history, endoscopic examination, high-resolution manometry (HRM), and barium esophagogram can help distinguish CES from achalasia $[3,6]$. While peroral endoscopic myotomy (POEM) has been gradually established as a minimally-invasive endoscopic treatment of achalasia and non-achalasia esophageal motility disorders, the ideal therapeutic strategy for CES remains controversial, and management often involves pneumatic balloon dilation (PBD) or surgical resection, depending on the CES type $[7,8]$.

In this case series, we report 6 patients referred to our institution with the presumed diagnosis of esophageal achalasia while emphasizing the salient features of adult/late-diagnosis CES that could help distinguish this entity from similar disorders. The feasibility, safety and short-term outcomes of POEM for CES are also examined and discussed.

\section{Patients and methods}

\section{Study population}

This is a retrospective, single-center study at Showa University Koto Toyosu Hospital, Tokyo, Japan between April 2014 and May 2019. Six patients with a "misdiagnosis" of achalasia established elsewhere, ultimately diagnosed with CES, referred to our institution for POEM, were included.

\section{Study outcome}

Symptom improvement (clinical success rate), defined as an Eckardt Symptom Score (ESS) of $\leq 3$ at 2-month follow up post-POEM, Satisfaction Score (from a scale of 0-10), decrease in Integrated Relaxation Pressure (IRP) over $4 \mathrm{sec}$, LES resting pressure, intrabolus pressure (IBP) and safety were assessed in this study.

\section{Preoperative evaluation and follow up}

A routine preoperative evaluation consisting of endoscopic examination, HRM, barium esophagogram, and computed tomography scan of the thorax and upper abdomen were done in all patients. All endoscopic examinations were performed under intravenous sedation with propofol (200 mg/ $20 \mathrm{~mL})$. Endoscopic examinations were carried out using highdefinition endoscopes (GIF-H260Z/GIF-H290Z, Olympus Corp., Tokyo, Japan). HRM was carried out using a 36-pressure sensors solid-state catheter (Unisensor, Switzerland) and a Starlet HRM assembly (Star Medical Inc., Tokyo, Japan). The normal upper limit for IRP with this catheter is $26 \mathrm{mmHg}$. Ten swallows of $5 \mathrm{~mL}$ water were recorded, the results of which were assessed using the Chicago Classification v3.0. During barium esophagogram, 2 barium swallows were performed and were recorded at a rate of 1 frame/sec for $20 \mathrm{sec}$. Two months post-POEM, all patients were scheduled to undergo endoscopic examination, HRM and barium esophagogram for re-evaluation.

\section{POEM technique}

POEM was carried out under general anesthesia using a single-channel endoscope (GIF-Q260J; Olympus) with a transparent distal attachment, and a triangle-tip knife with water jet function (TriangleTipKnifeJ KD-645; Olympus). The 2 operators who performed POEM have an experience of $>500$ POEM procedures each.

Electrocautery settings used for the procedure was similar to the preset POEM settings of the electrosurgical generator used in our institution (Erbe VIO300D; Erbe Elektromedizin $\mathrm{GmbH}$, Germany). For incision, EndoCut Q was used (effect 2 , duration 1, and interval 6). Submucosal dissection and tunneling was performed using Spray Coagulation (effect 2, 50 Watts). For hemostasis and coagulation of large vessels, Soft Coagulation was used (effect 5, 50 Watts).

After creating a mucosal incision, a submucosal tunnel was created similar to the original POEM technique. However, unlike POEM for achalasia, the submucosal tunnel cannot pass through the submucosa in the stenotic part (Fig. 1A). Consequently, a working space to replace the submucosal tunnel was created by incising the muscle layer proximal to the fibrostenotic segment. Based on our experience, the submucosal tunnel should be started approximately $5 \mathrm{~cm}$ proximal to the stenotic part to create adequate space to stabilize the endoscope. One to $2 \mathrm{~cm}$ proximal to the stenotic segment incision of both muscle layers or circular fibers alone is performed thus ensuring safe distance from the mucosa. Gradually, using spray coagulation or endocut currents, an incision of fibrotic tissue takes place and successful separation

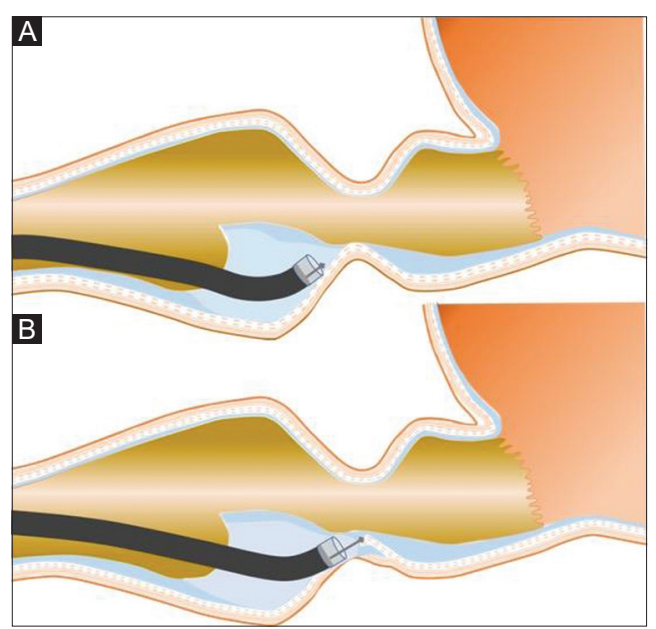

Figure 1 Illustration of peroral endoscopic myotomy technique in congenital esophageal stenosis (CES): (A) Unlike achalasia, the submucosal tunnel cannot pass through the submucosa in the stenotic area in CES; (B) A working space to replace the submucosal tunnel was created by incising the circular and longitudinal muscle layer proximal to the fibrostenotic segment 
of mucosal layer from the circular muscle-like tissue of the stenosis occurs (Fig. 1B,2; Supplementary Video 1). Distal to the stenosis tunnel, "resurfacing" will take place thus ensuring integrity of the majority of longitudinal muscle fibers. After completion of myotomy, 1 vial of gentamicin $(60 \mathrm{mg} / 1.5 \mathrm{~mL})$ diluted in $20 \mathrm{~mL}$ of normal saline was flushed into the tunnel. The entry site was then closed using clips.

\section{Ethical considerations}

The study protocol adhered to the principles of the Declaration of Helsinki and was approved by the Ethics Committee of Showa University Koto Toyosu Hospital (IRB Registration No: 19T7040).

\section{Results}

A total of 6 patients (median age: 40 [range: 18-58] years, 4 males) were included in this study.

\section{Clinical findings}

History revealed that all patients have been experiencing dysphagia for "as long as they can remember" and without any history of prior treatment. Chest pain, relieved by intake of water, was noted in 2 of 6 patients (Cases 2, 5; Table 1). Five patients (Cases 1-5) reported regurgitation as well. The average ESS before POEM for all patients was 4.2 (Table 2).

\section{Endoscopic findings}

Endoscopic examination revealed a ring-shaped stenosis located on the lower-third portion of the esophagus in 5 of 6 patients (Cases 1, 2, 3, 5 and 6). In one case (Case 4), a rosettelike configuration of the esophagogastric junction (EGJ) was recorded (Table 1; Fig. 3).

\section{HRM findings}

Esophageal HRM findings showed obstructed water passage (Table 1) as indicated by a compartmentalized intrabolus pressure pattern. This obstruction, however, was due to the fibrotic stenosis, not the LES, therefore, distinction between the stenotic area and the LES was possible in 4 of 6 patients (Cases 1, 2, 4 and 5; Fig. 4). In two cases (Cases 3 and 6), the distinction between the stenotic area and the LES through HRM alone seems rather challenging since the fibrostenotic part lies at the level of LES, hence, leading to a high IRP. The median LES pressure of all 6 patients was 44.35 (range: 15-59.6) $\mathrm{mmHg}$. The median IRP was 21.2 (range: 8.6-35.2) $\mathrm{mmHg}$. The median IBP was 22.9 (range: 12.8-32.9) $\mathrm{mmHg}$.

\section{Radiographic findings}

Barium esophagogram on 5 of 6 patients (Cases 1, 2, 4,5 and 6) revealed the presence of peristalsis and a visible esophageal lumen distal to the stricture (Table 1). This visible

\section{Table 1 Salient features of CES}

\begin{tabular}{|c|c|c|c|c|}
\hline Case No. & Clinical findings & Endoscopic findings & HRM findings & Barium esophagogram findings \\
\hline 1 & $\begin{array}{l}\text { + dysphagia, - chest pain, } \\
\text { + regurgitation }\end{array}$ & $\begin{array}{l}\text { Ring-shaped stenosis } \\
\text { with normal smooth } \\
\text { overlying mucosal lining }\end{array}$ & $\begin{array}{l}\text { Compartmentalized intrabolus } \\
\text { pressure pattern with distinction } \\
\text { between stenotic area and LES }\end{array}$ & Lopsided hourglass sign \\
\hline 2 & $\begin{array}{l}\text { + dysphagia, }+ \text { chest } \\
\text { pain, } \\
+ \text { regurgitation }\end{array}$ & $\begin{array}{l}\text { Ring-shaped stenosis } \\
\text { with normal smooth } \\
\text { overlying mucosal lining }\end{array}$ & $\begin{array}{l}\text { Compartmentalized intrabolus } \\
\text { pressure pattern with distinction } \\
\text { between stenotic area and LES }\end{array}$ & Lopsided hourglass sign \\
\hline 3 & $\begin{array}{l}\text { + dysphagia, - chest pain, } \\
\text { + regurgitation }\end{array}$ & $\begin{array}{l}\text { Ring-shaped stenosis } \\
\text { with normal smooth } \\
\text { overlying mucosal lining }\end{array}$ & $\begin{array}{l}\text { Compartmentalized intrabolus } \\
\text { pressure pattern but without } \\
\text { distinction between stenotic } \\
\text { area and LES }\end{array}$ & Similar to achalasia \\
\hline 4 & $\begin{array}{l}\text { + dysphagia, - chest pain, } \\
\text { + regurgitation }\end{array}$ & $\begin{array}{l}\text { Rosette-like } \\
\text { configuration }\end{array}$ & $\begin{array}{l}\text { Compartmentalized intrabolus } \\
\text { pressure pattern with distinction } \\
\text { between stenotic area and LES }\end{array}$ & Lopsided hourglass sign \\
\hline 5 & $\begin{array}{l}+ \text { dysphagia, }+ \text { chest } \\
\text { pain, } \\
+ \text { regurgitation }\end{array}$ & $\begin{array}{l}\text { Ring-shaped stenosis } \\
\text { with normal smooth } \\
\text { overlying mucosal lining }\end{array}$ & $\begin{array}{l}\text { Compartmentalized intrabolus } \\
\text { pressure pattern with distinction } \\
\text { between stenotic area and LES }\end{array}$ & Lopsided hourglass sign \\
\hline 6 & $\begin{array}{l}+ \text { dysphagia, - chest pain, } \\
\text { - regurgitation }\end{array}$ & $\begin{array}{l}\text { Ring-shaped stenosis } \\
\text { with normal smooth } \\
\text { overlying mucosal lining }\end{array}$ & $\begin{array}{l}\text { Compartmentalized intrabolus } \\
\text { pressure pattern but without } \\
\text { distinction between stenotic } \\
\text { area and LES }\end{array}$ & Lopsided hourglass sign \\
\hline
\end{tabular}


Table 2 Pre- and post-POEM data

\begin{tabular}{lcccccccccc}
\hline Case No. & $\begin{array}{c}\text { Pre-POEM } \\
\text { ESS }\end{array}$ & $\begin{array}{c}\text { Post-POEM } \\
\text { ESS }\end{array}$ & $\begin{array}{c}\text { Pre-POEM } \\
\text { LES Mean } \\
\text { pressure } \\
(\mathrm{mmHg})\end{array}$ & $\begin{array}{c}\text { Post-POEM } \\
\text { LES Mean } \\
\text { pressure } \\
(\mathrm{mmHg})\end{array}$ & $\begin{array}{c}\text { Pre-POEM } \\
\text { IRP } \\
(\mathrm{mmHg})\end{array}$ & $\begin{array}{c}\text { Post-POEM } \\
\text { IRP } \\
(\mathrm{mmHg})\end{array}$ & $\begin{array}{c}\text { Pre-POEM } \\
\text { IBP } \\
(\mathrm{mmHg})\end{array}$ & $\begin{array}{c}\text { Post-POEM } \\
\text { IBP } \\
(\mathrm{mmHg})\end{array}$ & $\begin{array}{c}\text { Post-POEM } \\
\text { satisfaction } \\
\text { score }\end{array}$ \\
\hline 1 & 4 & N/A & 21.4 & N/A & 8.6 & N/A & 12.8 & N/A & N/A \\
\hline 2 & 7 & N/A & 27 & N/A & 22.8 & N/A & 28.4 & N/A & N/A \\
\hline 3 & 4 & 2 & 68.6 & 13.9 & 35.2 & 14 & 18.3 & 7.9 & 9 \\
\hline 4 & 4 & 2 & 37.4 & 9.4 & 19.6 & 2.8 & 32.9 & 19.2 & 10 \\
\hline 5 & 3 & 0 & 51.3 & 9.4 & 16.1 & 9.9 & 27.5 & 1.5 & 9 \\
6 & 3 & 1 & 59.8 & 18.7 & 25.6 & 17.4 & 14.1 & 4.3 & 10 \\
\hline
\end{tabular}

POEM, peroral endoscopic myotomy; ESS, Eckardt Symptom Score; LES, lower esophageal sphincter; IRP, integrated relaxation pressure; IBP, intrabolus pressure N/A, not applicable
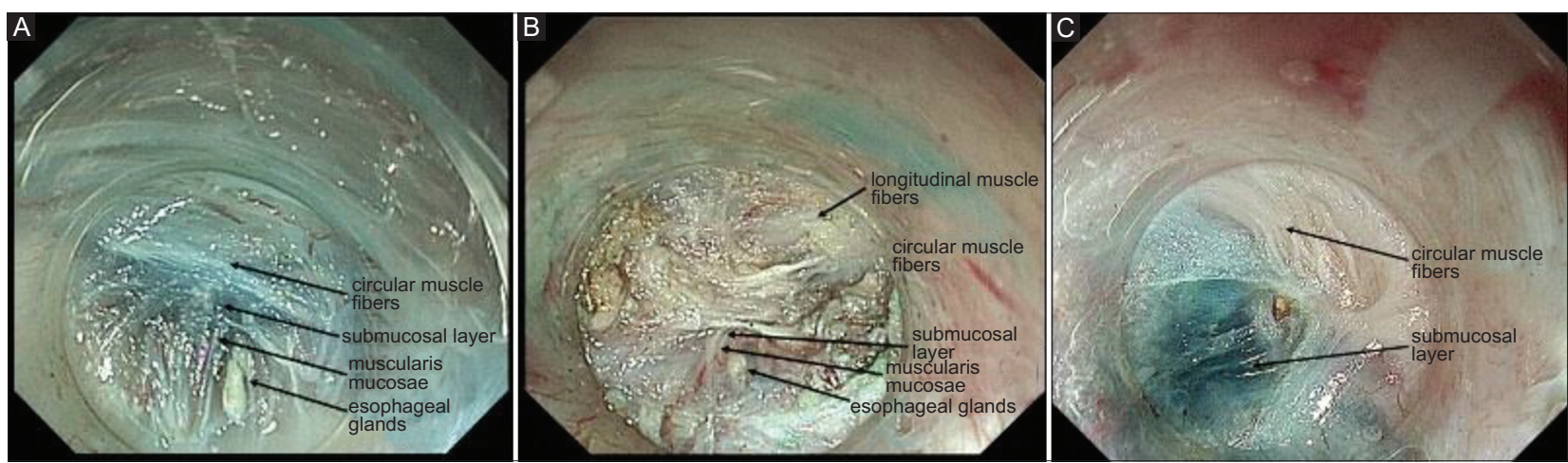

Figure 2 Peroral endoscopic myotomy (POEM) in congenital esophageal stenosis (CES): Creating the submucosal tunnel during POEM in CES (B) and (C); the muscularis mucosa is encountered since the submucosal layer is narrow in CES (A) and (B). 1-2 cm proximal to the stenotic segment incision of both muscle layers or circular fibers alone is performed thus ensuring safe distance from the mucosa (B). In contrast with POEM in achalasia (C), the submucosal tunnel is created without encountering the muscularis mucosa.

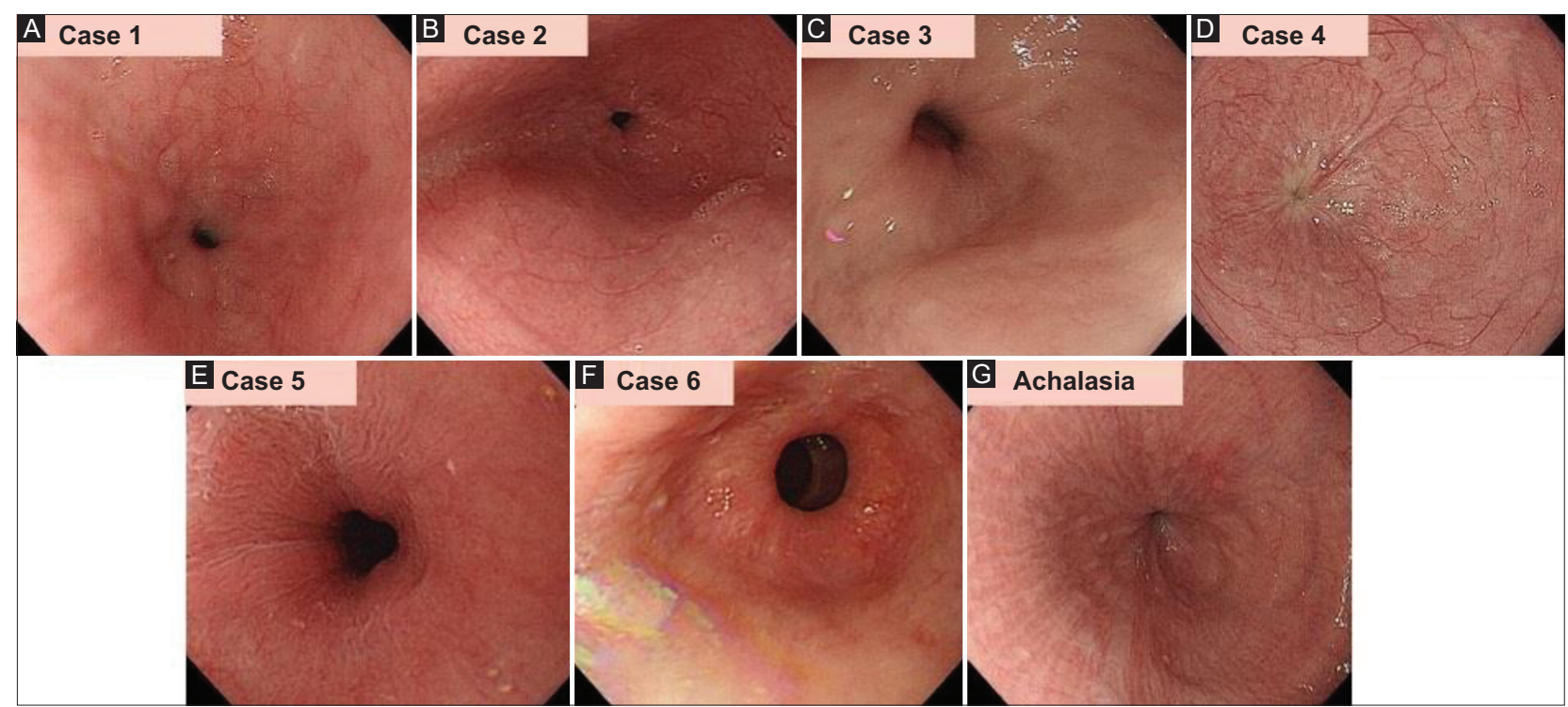

Figure 3 Endoscopic findings of congenital esophageal stenosis (CES) (A) to (F) showing a ring-shaped stenosis with a normal smooth overlying mucosa, except for Case $4(D)$, as compared to achalasia $(G)$ where a rosette-like configuration is evident

esophageal lumen distal to the stricture created a "lopsided hourglass" image. One case (Case 3) did not present with the "lopsided hourglass sign" and seemed to mimic that of achalasia. In addition, when an invisible horizontal line is 


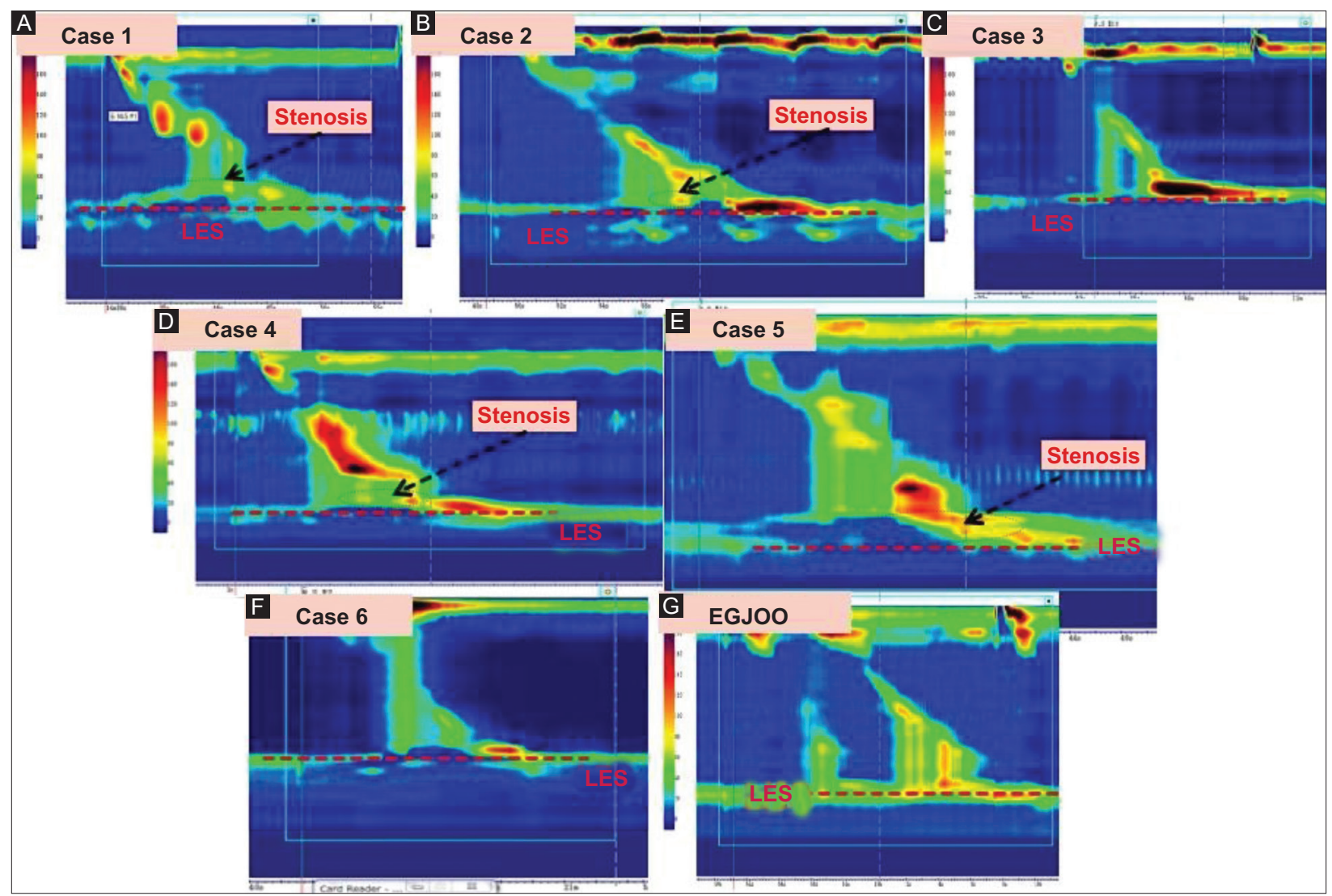

Figure 4 High-resolution manometric findings showed hindered/obstructed water passage as indicated by a compartmentalized intrabolus pressure pattern. The obstruction, however, was made by the stenosis, not the lower esophageal sphincter (LES), therefore, distinction between the stenotic area and the LES was possible in 4 of 6 cases (A, B, D, E). In 2 cases (C, F), the distinction between the stenotic area and the LES was impossible since the stenotic part was coinciding with the LES

EGJOO, esophagogastric junction outflow obstruction

drawn on the top of the dome of the left diaphragm, the location of stenosis in 4 patients (Cases 1, 2, 5 and 6) were above this line, proximal to the LES (Fig. 5). Five cases (Cases $1,2,3,4$ and 6) also showed a dilated esophagus.

\section{Treatment with POEM}

POEM was attempted in all 6 cases. POEM could not be completed on the first 2 patients due to difficulty in exposing, dissecting the submucosa and advancing through the stenotic area. POEM was completed successfully on the subsequent 4 patients. Among the 4 successful POEM cases, all had an improvement in ESS to $<3$ at the 2-month follow up (Table 2); hence, a clinical success rate of $100 \%$. Barium esophagogram findings at 2 months post-POEM also showed a marked improvement in the passage of contrast through the previously stenotic area (Fig. 6). On HRM, all had a decrease in the IRP and IBP at the 2-month follow up (Table 2). PostPOEM median IRP was 11.2 (range: $2.8-17.4) \mathrm{mmHg}$, and post-POEM median IBP was 6.1 (range: $1.5-19.2) \mathrm{mmHg}$. The average satisfaction score 2 months post-POEM was 9.5 of 10 .

\section{Discussion}

In the present case series, the experience drawn in a referral center for POEM, from the work-up and management of CES, is presented. Six cases of CES in adults treated with POEM were retrospectively assessed. To our knowledge, this study is the first reporting successful POEM in CES [6].

Histologic evaluation is considered the gold standard in making a definite diagnosis [6] and categorizing CES into 3 types: 1) tracheobronchial remnants (TBR) -most common type and seen more often in the lower esophagus; 2) fibromuscular thickening (FMT); and 3) membranous web (MW) -least common and occurring in the upper and midesophagus) [9].

Typically, CES patients present with a long-standing history of dysphagia to solid foods beginning in early childhood $[10,11]$. Patients eventually seek medical consult as adults due to superimposed episodes of food impaction. In our study, all our patients, when asked about the duration and onset of symptoms, stated that they have been experiencing their symptoms for "as long as they can remember".

During endoscopic examination, the presence of ringlike configuration in the area of stenosis with normal smooth overlying mucosal lining has been described as the typical 


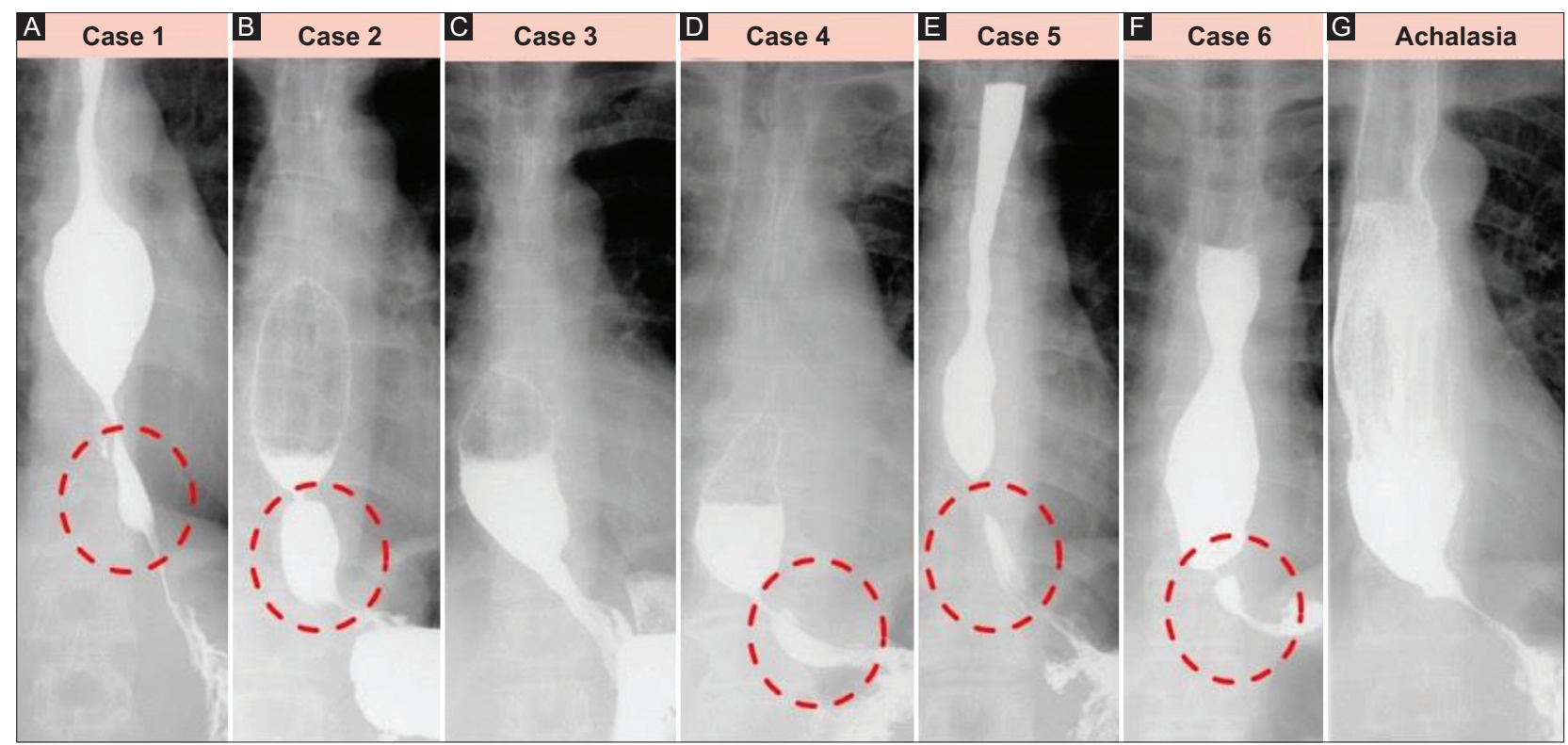

Figure 5 Barium esophagogram findings of congenital esophageal stenosis (A) to (F), showing visible esophageal lumen distal to the stricture (red circles) that we coined as "lopsided hourglass sign", except for Case 3 (C), as compared to achalasia (G)
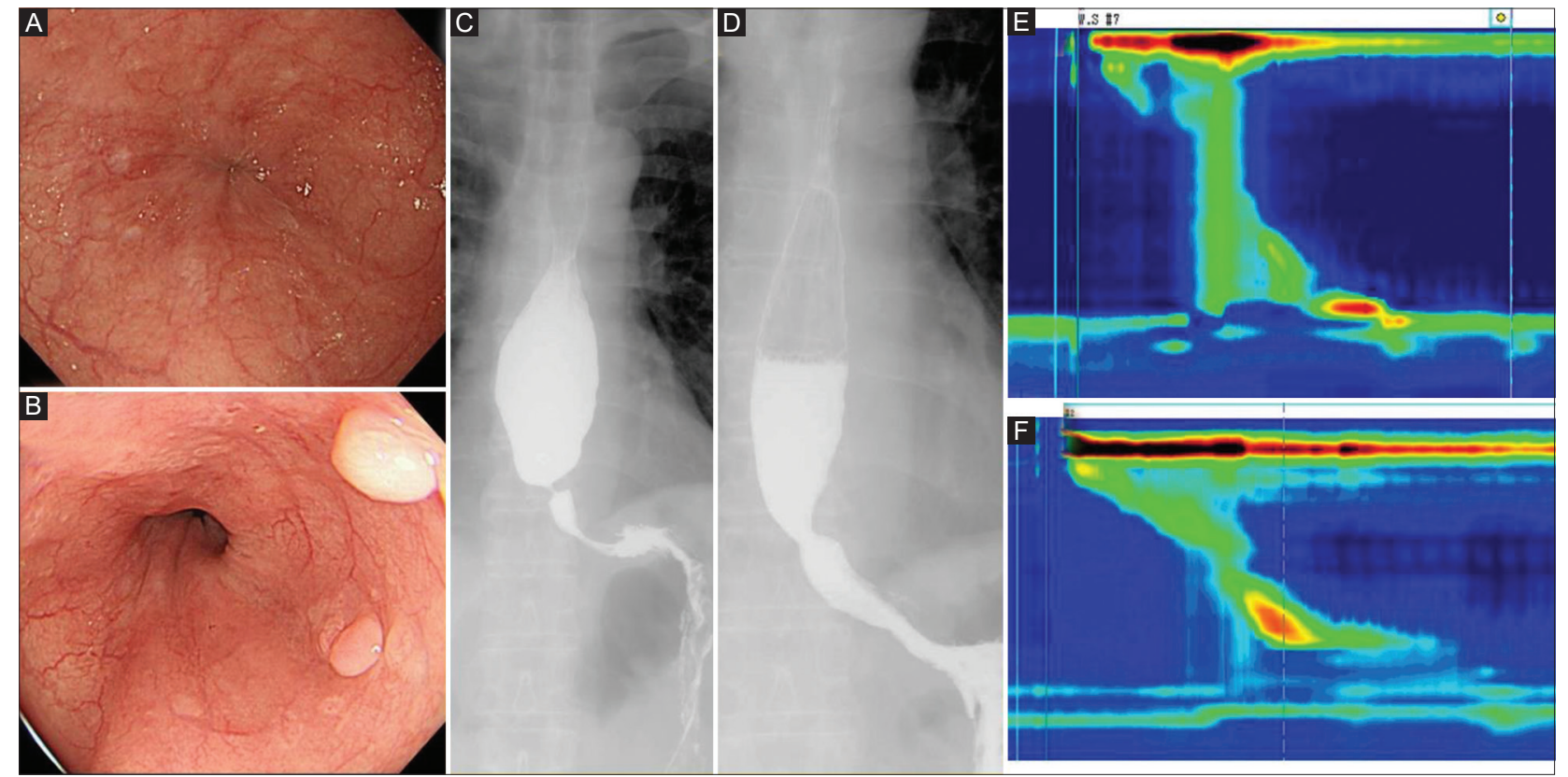

Figure 6 One case example (Case 6) showing pre-peroral endoscopic myotomy (POEM) and 2-month post-POEM findings. (A) shows pre-POEM endoscopic examination, (B) 2-month post-POEM endoscopic finding. Barium esophagogram shows a marked improvement in the passage of contrast through the previously stenotic area during the 2-month follow-up barium swallow (D), compared to pre-POEM (C). (E) shows highresolution manometric (HRM) findings pre-POEM, (F) HRM findings at 2 months post-POEM

CES endoscopic finding [12]. In contrast, a rosette-like configuration at the EGJ [13] and the "champagne-glass" sign [14] are characteristic for achalasia. In the present study, majority presented with the typical ring-shaped stenosis.

Barium esophagogram aids in the detection of stricture location and the presence of ring-like constrictions, typical CES radiographic findings [1,3]. Strictures may be seen as abrupt (more often associated with TBR) or tapered (seen in FMT) stenotic lesions anywhere in the esophagus and separate from the EGJ [15-17]. On the other hand, achalasia typically shows aperistalsis, dilated esophagus, contrast pooling, and bird-beak sign [18]. Interestingly, in majority of our patients, we have detected a distinct visible esophageal lumen distal to the stricture, and we coined it as "lopsided hourglass sign", which encouraged us to utilize it as a key point in identifying CES by barium esophagogram, 
although further evaluation is still warranted to validate this finding.

For HRM in CES, synchronous esophageal contractions are predominantly noted in FMT and TBR variants while peristaltic esophageal contractions are seen in MW type $[6,19]$. In our study, all cases had normal peristalsis in HRM and barium esophagogram. Areas with high pressurization above or on the LES were observed, which corresponded with the stenotic part in barium esophagogram or endoscopic examination. The compartmentalized pressurization between the normal peristalsis and stenotic part, suggesting obstruction made by the stenosis, seemed to be characteristic to CES. If the stenosis can be distinguished from the LES on HRM and establish that the LES is relaxed, distinguishing CES and EGJ outflow obstruction (EGJOO) can be possible. On the other hand, if the LES is very close to the stenosis, as in case 3, it is difficult to differentiate CES from EGJOO (Fig. 4).

Treatment of CES depends on the severity, location and type of CES. Minimally invasive treatments such as PBD [20,21], and myotomy [17,22] are the preferred options for FMT and MW, whereas surgical interventions are often reserved for unsuccessful cases and for TBR [16,17]. In the present case series, we attempted to perform POEM on all 6 patients, however, our results were slightly variable. POEM could not be completed for the first 2 patients due to difficulty in exposing and dissecting the submucosa, and we could not get past the focal yet extremely dense fibrosis of the stenotic area. Additional several post-POEM balloon dilatations were performed on both patients. In the remaining 4 patients, POEM was completed successfully after making a refinement on the original POEM technique.

Although the present study showed favorable short-term outcomes, this is not the first to attempt POEM in an adult patient with CES [6]. However, in the said report by Liu et al, mucosal perforation occurred, and POEM was converted to a partial esophageal resection. This shows that due to the technical difficulty of POEM in CES, mucosal perforation may easily occur, which may potentially lead to life-threatening adverse events. The definite role of POEM in CES treatment remains to be established, although it seems to appear as an alternative treatment, other than surgical intervention, for CES patients who fail dilation.

At this point, certain study limitations must be acknowledged. The diagnosis of CES in our patients could not be absolutely confirmed due to the lack of definitive histologic evaluation. Biopsy during POEM procedure for histologic confirmation should be performed in future studies when CES is suspected. Our experience of treating CES patients with POEM is still rather limited. Although favorable short-term POEM outcomes have been achieved, conclusions could not be drawn on whether POEM is equally effective in all types of CES. While our strategy seems effective, the technical difficulty still hinders its standardization as a treatment for CES, and an inexperienced operator should not attempt POEM on CES patients.

Overall, in patients presenting with long-standing history of dysphagia arising from childhood and persisting into adulthood, it is important to consider a differential diagnosis of CES in adults. Coevaluation of the medical history with endoscopic, barium esophagogram, and HRM findings is of paramount importance in establishing an accurate diagnosis of CES in adults.

Supplementary Video 1 Peroral endoscopic myotomy technique in congenital esophageal stenosis: The submucosal tunnel should be started approximately $5 \mathrm{~cm}$ proximal to the stenotic part in order to create adequate space to stabilize the endoscope. One to $2 \mathrm{~cm}$ proximal to the stenotic segment incision of both muscle layers or circular fibers alone is performed thus ensuring safe distance from the mucosa. Gradually, using spray coagulation or endocut currents, an incision of fibrotic tissue takes place and successful separation of mucosal layer from the circular muscle-like tissue of the stenosis occurs

You can see: https://youtu.be/ZlgX4E3qKnA

\section{Summary Box}

\section{What is already known:}

- Congenital esophageal stenosis (CES) in adults is a rare disorder that can present as achalasia, particularly in the distal esophagus

- The ideal therapeutic strategy for CES often involves pneumatic balloon dilation (PBD) or surgical resection, depending on the CES type

- Coevaluation of the medical history with endoscopic, barium esophagogram, and highresolution manometric findings is of paramount importance in establishing an accurate diagnosis of CES in adults

\section{What the new findings are:}

- Salient features of CES in adults include the following: a long-standing history of dysphagia, ring-shaped stenosis on endoscopic examination, "lopsided hourglass" sign on barium esophagogram, and high-resolution manometry findings indicated by a compartmentalized intrabolus pressure pattern with distinction between the stenotic area and the lower esophageal sphincter

- POEM appears as an alternative treatment, other than surgical intervention, for CES patients who fail dilation

\section{References}

1. Oh $\mathrm{CH}$, Levine MS, Katzka DA, et al. Congenital esophageal stenosis in adults: clinical and radiographic findings in seven patients. AJR Am J Roentgenol 2001;176:1179-1182.

2. Suzuhigashi M, Kaji T, Noguchi H, et al. Current characteristics 
and management of congenital esophageal stenosis: 40 consecutive cases from a multicenter study in the Kyushu area of Japan. Pediatr Surg Int 2017;33:1035-1040.

3. Katzka DA, Levine MS, Ginsberg GG, et al. Congenital esophageal stenosis in adults. Am J Gastroenterol 2000;95:32-36.

4. Tuason J, Inoue H. Current status of achalasia management: a review on diagnosis and treatment. J Gastroenterol 2017;52:401406.

5. Inoue $\mathrm{H}$, Shiwaku $\mathrm{H}$, Iwakiri $\mathrm{K}$, et al. Clinical practice guidelines for peroral endoscopic myotomy. Dig Endosc 2018;30:563-579.

6. Liu Q, Yao LP, Xie HH, et al. High-resolution manometry and endoscopic ultrasonography are important for diagnosing congenital esophageal stenosis. J Dig Dis 2015;16:479-482.

7. Dall'Oglio L, Caldaro T, Foschia F, et al. Endoscopic management of esophageal stenosis in children: New and traditional treatments. World J Gastrointest Endosc 2016;8:212-219.

8. Yasuda JL, Staffa SJ, Clark SJ, et al. Endoscopic incisional therapy and other novel strategies for effective treatment of congenital esophageal stenosis. J Pediatr Surg 2020;55:2342-2347.

9. Terui K, Saito T, Mitsunaga T, Nakata M, Yoshida H. Endoscopic management for congenital esophageal stenosis: A systematic review. World J Gastrointest Endosc 2015;7:183-191.

10. Younes Z, Johnson DA. Congenital esophageal stenosis: clinical and endoscopic features in adults. Dig Dis 1999;17:172-177.

11. Bhaskar SK, Bin-Sagheer S, Brady PG. Congenital esophageal stenosis. Dig Dis 2000;18:186.

12. Pokieser P, Schima W, Schober E, Bohm P, Stacher G, Levine MS. Congenital esophageal stenosis in a 21-year-old man: clinical and radiographic findings. AJR Am J Roentgenol 1998;170:147-148.

13. Iwakiri K, Hoshihara Y, Kawami N, et al. The appearance of rosette- like esophageal folds ("esophageal rosette") in the lower esophagus after a deep inspiration is a characteristic endoscopic finding of primary achalasia. J Gastroenterol 2010;45:422-425.

14. Gomi $\mathrm{K}$, Inoue $\mathrm{H}$, Ikeda $\mathrm{H}$, et al. New endoscopic classification of the cardiac orifice in esophageal achalasia: Champagne glass sign. Dig Endosc 2016;28:645-649.

15. Jain V, Yadav DK, Sharma S, Jana M, Gupta DK. Management of long segment congenital esophageal stenosis: A novel technique. J Indian Assoc Pediatr Surg 2016;21:150-152.

16. Kurian JJ, Jehangir S, Varghese IT, Thomas RJ, Mathai J, Karl S. Clinical profile and management options of children with congenital esophageal stenosis: A single center experience. J Indian Assoc Pediatr Surg 2016;21:106-109.

17. Takamizawa S, Tsugawa C, Mouri N, et al. Congenital esophageal stenosis: Therapeutic strategy based on etiology. J Pediatr Surg 2002;37:197-201.

18. Ishii T, Akaishi T, Abe M, et al. Importance of Barium Swallow Test and Chest CT Scan for Correct Diagnosis of Achalasia in the Primary Care Setting. Tohoku J Exp Med 2019;247:41-49.

19. Kawahara H, Oue T, Okuyama H, Kubota A, Okada A. Esophageal motor function in congenital esophageal stenosis. J Pediatr Surg 2003;38:1716-1719.

20. Dominguez R, Zarabi M, Oh KS, Bender TM, Girdany BR. Congenital oesophageal stenosis. Clin Radiol 1985;36:263-266.

21. Vergos M, Chapuis O, Lhomme Desages B, Messina MH. Congenital stenosis of the esophagus. A rare diagnosis in children and adults. J Chir (Paris) 1992;129:16-19.

22. Longcroft-Wheaton G, Ellis R, Somers S. Dysphagia in a 30-yearold woman: too old for a congenital abnormality? Br J Hosp Med (Lond: 2005) 2010;71:170-171. 